\title{
Further Statement at Opening of World Clean Energy Conference
}

T $\mathrm{t}$ is both an honour and a pleasure for me to address you on the occasion of the World Clean Energy Conference. Indeed, I am grateful to the Organizing Committee for according me this opportunity. The primary source of energy for cooking and water-heating in the rural areas of developing Africa, Asia, Latin America, and the Pacific, is firewood. Most low- and middle-income urban households in those areas depend on a combination of charcoal and kerosene for their basic energy needs, whereas the higher-income groups, particularly in the urban areas, have access to other forms of energy, for example electricity and gas. Other energy-intensive activities in those countries include transportation, industry, space-cooling, and entertainment. For these activities, fossil fuel and electricity are the primary energy-sources.

One thing is clear: expanding populations will lead to more use of firewood, charcoal, and kerosene. Additionally, the need for accelerated industrialization, and the need to improve both private and public transport for more people, will increase the demand for, and consumption of, fossil fuels and electricity. The situation in the developed world is no less disheartening. It is known, for example, that in the developed-market economies, fossil-fuel energy consumption grew at an annual rate of 4\% between 1950 and 1970, dropping to $0.4 \%$ between 1970 and 1985 , for reasons which we all know. Nonetheless, the rate of growth over the entire period of 1950 to 1985 averaged $3.6 \%$ annually.

\section{Energy Use Increasing}

It is evident that, whether you look north or south, energy demand and energy consumption are on an upward swing. This trend makes it imperative that the search for less harmful ways of producing and using energy be intensified. The solution cannot well be the enforcement of reduced energy consumption. The Intergovernmental Panel on Climate Change (IPCC) recommends that, in implementing strategies aimed at reducing the rate of climate change, we must focus on those policies which have multiple social, economic, and environmental, benefits. The Panel also advised that we must consider, first, those measures which are technically and commercially proven, and are beneficial in their own right.

These recommendations are very pertinent to our deliberations today. Indeed, if you accept them, as I do, then the concept of clean energy must be on top of the global environment agenda. Adoption of a clean energy strategy and the widespread implementation of such a strategy have innumerable social, economic, and environmental, benefits.

First, irrespective of whether you are in a rural setting in a developing country depending on firewood as the primary source of energy, or instead in an urban environment in the same country depending on charcoal and kerosene, these sources are not inexhaustible. It was José Goldemberg, now Brazilian Minister of Science \& Technology, and others who, in 1985, stated that, at the present rate of consumption, the world's remaining oil resources that can be ultimately recovered amount to less than a 100 years' supply.

\section{Advocacy of Solar Sources}

When we search for and use clean energy sources, we are also conserving current energy sources for future generations, so that there will be something to supplement what new technologies will produce at that time. When we advocate the development and widespread use of solar energy — and I am a firm believer in this - we are calling for the use of a clean and inexhaustible form of energy. But we are also calling for a reduction in the excessive use of firewood, charcoal, and fossil fuels, so that these can be exploited in future with advanced technologies which can render them relatively clean. We should also call for more extensive use of wind power, and of geothermal sources where the latter exist.

Another significant benefit from the adoption of clean energy strategies is the cleaning up of our cities. We know of ailments, suffered by the inhabitants of large cities, that result from fumes produced by charcoal and fossil-fuel burning. It is not unusual to observe buildings in some cities coated with soot from chimneys and automobile exhausts. It would be unrealistic to imagine that such coatings leave the inhabitants unaffected. We also know what effects emissions from traditional energy sources can have had on soils, on forests and other vegetation in general, and on our freshwater supplies. Some of these emissions are responsible for the wellknown acid rain.

\section{Atmospheric Composition Affecting Climate}

Having briefly referred to other benefits of a clean energy strategy in other areas, permit me to turn to the question of climate change. During the period 1950-85, the estimated global injection of carbon into the atmosphere resulting from emissions of carbon dioxide rose from 1.5 to 5.3 Gigatonnes per year as a result of global energy consumption. The total input of carbon into the atmosphere averaged 7 Gigatonnes per year during the 1980s, with emissions from fossil fuels accounting for almost $80 \%$ and deforestation and land-use contributing the rest. Indeed the atmospheric concentration of carbon dioxide has increased from $310 \mathrm{ppmv}$ in 
1950 to approximately $353 \mathrm{ppmv}$ in 1990 . This increase is attributable, in the main, to energy production and use, and to deforestation and changes in land-use practices.

The atmospheric concentration of other 'greenhouse' gases, notably methane, nitrous oxide, and chlorofluorocarbons, is also increasing. More than $20 \%$ of the annual release of methane into the atmosphere is contributed by energy-related activities, namely gas drilling, coal mining, and biomass burning. Energy-related activities, for example combustion and biomass burning, also contribute to the nitrous oxide budget.

As a meteorologist, I know that the global climate system is closely associated with the radiative properties of the atmosphere. I also know that the radiative properties of the atmosphere are determined by its composition. Hence, as we modify the composition of the atmosphere, we also modify its radiative properties, and this is most likely to have a significant effect on the global climate system.

There is now consensus among the world's scientists that the significant effect is a change in climate, including global warming. Indeed, the IPCC observed that more than $50 \%$ of the radiative forcing of climate is attributable to anthropogenic sources of 'greenhouse' gases from the energy sector.

\title{
Need for Global Counteraction
}

The social, economic, and environmental, impacts of climate change and global warming have been the subject of intense national, regional, and international, debate for the last decade, and I do not need to repeat them here. However, they are so far-reaching that we cannot wait to see them happen before we act. Action, indeed, has been initiated. The WMO Congress, during its tenth session in 1987 , called for the establishment of a mechanism which would continuously assess the various aspects of climate change - a decision which led to the joint WMO/UNEP IPCC. Last year, the UN General Assembly established the Intergovernmental Negotiating Committee (INC) for a Framework Convention on Climate Change. Your Conference starting today, and all that you stand for, are part of this concerted action against one of the most serious environmental problems of this century.

Now I believe I have underscored the importance and urgency of adopting a clean energy policy, and hence the significance of your deliberations over the next four days, in which I wish you all success.

\author{
G.O. Patrick Obasi, Secretary-General \\ World Meteorological Organization \\ Avenue Giuseppe-Motta 41 \\ 1211 Geneva 20 \\ Switzerland.
}

\section{Request Statement: Energy and The Biosphere}

T am honoured to have been asked - on this auspicious occasion which we hope will be the first of an ongoing series on its developing theme of the utmost importance - to speak briefly on the challenging topic of energy and The Biosphere. This Biosphere is of course the layer around the Earth in which life occurs naturally, and it is this, in its relative fragility, which is really threatened - rather than the more solid interior of our planet.

Consequently we must surely all agree that The Biosphere has to be brought back to balance - despite the appalling ravages of our energy-intensive modern civilization - if we are to enjoy at all equable continuation of life on Earth. Of this key imperative the world will have to be duly apprised through suitable education and chronic reminders such as the latterly-established Biosphere Day, in the original Declaration of which, as published in the Autumn 1991 issue (vol. 18, p. 199) of Environmental Conservation, it is clarified that

'The Biosphere is that favoured layer of our planet's periphery (solid, liquid, and gaseous) in which any form of life exists naturally. It is our sole home and living heritage whose protection should be our first human imperative. Energized in virtual eternity by the Sun, The Biosphere is our only proven life-support — as the world is at last beginning to realize, while concomitantly recognizing the immense implications of this most basic fact. It is also the only proven venue of organized life in our Universe, hence multiplying our gargantuan responsibilities to safeguard it in every possible way.'

Humans being possessed of unique intelligence and hence capability among the world's teeming biota, the basic need is for each and every one of them to be suitably enlightened and duly persuaded to place, in all their thinking and acting, the welfare of The Biosphere before any personal selfish or factional consideration. That is what we have to aim at and strive for if our world is to be saved continuingly for future generations.

May this first World Clean Energy Conference and the Global Energy Charter (see the following pageand-a-half of Environmental Conservation) take us already a big step forward towards adequately sustainable development with due realization of Humankind's most urgent need to re-establish the balance of The Biosphere. 